\title{
Tunicamycin sensitizes human prostate cells to TRAIL-induced apoptosis by upregulation of TRAIL receptors and downregulation of cIAP2
}

\author{
YOUNG-HWA JUNG ${ }^{1}$, EUN JIN LIM ${ }^{1}$, JEONGHOON HEO $^{1,3}$, TAEG KYU KWON ${ }^{2}$ and YOUNG-HO KIM ${ }^{1,3}$ \\ ${ }^{1}$ Department of Molecular Biology and Immunology, Kosin University College of Medicine, Busan 602-703; \\ ${ }^{2}$ Department of Immunology, Keimyung University School of Medicine, Taegu 700-172; \\ ${ }^{3}$ Institute for Medical Sciences, Kosin University, Busan 602-703, Republic of Korea
}

Received December 21, 2011; Accepted February 23, 2012

DOI: 10.3892/ijo.2012.1402

\begin{abstract}
The addition of tunicamycin to prostate cancer cells enhances cell death mediated by tumor necrosis factorrelated apoptosis-inducing ligand (TRAIL). In this study, we investigated whether tunicamycin, an endoplasmic reticulum stress inducer, can potentiate TRAIL-induced apoptosis in human prostate cancer cells. We evaluated the combination of tunicamycin and TRAIL and found synergistic promotion of apoptosis in prostate cancer cells. The combined treatment with tunicamycin and TRAIL significantly induced apoptosis, and stimulated caspase- $3,-8$ and -9 activity, as well as the cleavage of poly (ADP-ribose) polymerase. We found that tunicamycin promoted TRAIL-induced apoptosis by the upregulation of death receptor (DR)4 and DR5 and the downregulation of cellular inhibitor of apoptosis 2 (cIAP2). In addition, downregulation of cIAP2 expression using small interfering RNA significantly attenuated the apoptosis induced by TRAIL. Taken together, our results demonstrate that the combination of tunicamycin and TRAIL may provide a novel strategy for treating prostate cancer by overcoming critical mechanisms of apoptosis resistance.
\end{abstract}

\section{Introduction}

Tumor necrosis factor-related apoptosis-inducing ligand (TRAIL) induces apoptosis selectively in cancer cells in vitro and in vivo and has little or no cytotoxicity to normal cells (1-5). The potential significance of TRAIL as an anticancer agent is supported by its selective toxicity to human tumor xenografts

Correspondence to: Dr Young-Ho Kim, Department of Molecular Biology and Immunology, Kosin University College of Medicine, 34 Amnam-dong, Seo-gu, Busan 602-703, Republic of Korea E-mail:kimyh@kosin.ac.kr

Key words: tunicamycin, cellular inhibitor of apoptosis 2, tumor necrosis factor-related apoptosis-inducing ligand, apoptosis, death receptor but not normal tissues in animal models $(1,2)$. TRAIL is therefore a promising agent for cancer therapeutics. However, many tumors remain resistant to treatment with TRAIL.

One of the hallmark features of cancer is the ability to evade apoptosis, particularly by the upregulation of anti-apoptotic genes, such as certain members of the Bcl-2 (6) and inhibitor of apoptosis (IAP) protein families (7). IAPs, particularly cellular IAP1 (cIAP1), cIAP2 and X-linked IAP (XIAP), function to evade cell death by preventing the activation of caspase- 8 or inhibiting the activity of caspase- $9,-3$ and -7 (8-10). cIAP1 and cIAP2 possess an E3 ubiquitin ligase domain that promotes their proteasome-dependent degradation, together with other targets $(11,12)$. In prostate cancer cells, the targeted inhibition of survivin increases sensitivity to flutamide (13) and paclitaxel (14). XIAP inhibition has been reported to increase sensitivity to cisplatin (15), while an antisense oligonucleotide targeting XIAP has shown promise in preclinical studies (16). However, little is known about the effect of specifically targeting cIAP1 or cIAP2 in prostate cancer cells. In addition, while a number of studies have investigated the effects of the knockdown of individual IAPs on cell survival (17-21), few studies have examined the effect of the knockdown of multiple IAPs.

In this study, we investigated whether IAP knockdown can sensitize prostate cancer cells to apoptosis, and determined the relative contribution of cIAP2 to this process. We investigated both the effect on cell death, and the impact of the specific inhibition of cIAP2 on the survival of prostate cancer cells. Our results demonstrate that the combined knockdown of cIAP2 and TRAIL is required to significantly enhance cytotoxicity in DU-145 cells. This effect was caspase-dependent and specific for TRAIL treatment. This study therefore demonstrates the importance of targeting cIAP2 to enhance sensitivity to TRAILinduced apoptosis, and suggests that tumor cell survival may be inhibited by specific targeting, including that of cIAP2.

\section{Materials and methods}

Cell culture and survival assay. DU-145 prostate cells were obtained from the American Type Culture Collection (Manassas, VA, USA). Cells were cultured in RPMI-1640 medium (Gibco-BRL, Gaithersburg, MD, USA) containing 
$10 \%$ heat-inactivated fetal bovine serum (HyClone, Logan, UT, USA), penicillin (100 U/ml), streptomycin (100 U/ml) and $26 \mu \mathrm{M}$ sodium bicarbonate for monolayers. Cells were kept in a $37^{\circ} \mathrm{C}$ humidified incubator with a mixture of $95 \%$ air and $5 \% \mathrm{CO}_{2}$. One day prior to the experiment, cells were plated into 60-mm dishes. Tunicamycin (Sigma-Aldrich) was added directly to the cell cultures at the indicated concentrations. For the trypan blue exclusion assay, trypsinized cells were pelleted and resuspended in $0.2 \mathrm{ml}$ of medium, $0.5 \mathrm{ml}$ of $0.4 \%$ trypan blue solution, and $0.3 \mathrm{ml}$ of phosphate-buffered saline (PBS). Samples were mixed thoroughly, incubated at room temperature for $15 \mathrm{~min}$ and examined under a light microscope. At least 300 cells were counted for each survival determination.

Reagents. Recombinant human TRAIL ligand was obtained from Koma Biotech Inc. (Seoul, Korea). Tunicamycin was obtained from Sigma Chemical Co. (St Louis, MO, USA). Z-VAD-fmk was purchased from Calbiochem (San Diego, CA, USA) and a stock solution was prepared in DMSO. Polyclonal anti-poly (ADP-ribose) polymerase (PARP), anti-Bc1-X ${ }_{L}$, anti-Mcl-1, anti-death receptor (DR)5, anti-DR4, anti-DcR2 and anti-actin antibodies were purchased from Santa Cruz Biotechnology (Santa Cruz, CA, USA); anti-XIAP, anti-cIAP-1 and anti-cIAP-2 from R\&D Systems (Minneapolis, MN, USA); anti-caspase-3 and anti-caspase- 9 from Cell Signaling Technology; and anti-FLIP from Calbiochem. Monoclonal antibodies were purchased from the following companies: anticaspase- 8 from Upstate Biotechnology and anti-Bcl-2 from Santa Cruz.

Western blot analysis. Cells were lysed with 1X Laemmli lysis buffer (2.4 M glycerol, 0.14 M Tris, pH 6.8,0.21 M SDS, 0.3 mM bromophenol blue) and boiled for $10 \mathrm{~min}$. Protein content was measured with BCA Protein Assay Reagent (Pierce, Rockford, IL, USA). The samples were diluted with $1 \mathrm{X}$ lysis buffer containing $1.28 \mathrm{M} \beta$-mercaptoethanol, and equal amounts of protein were loaded on $10 \%$ SDS-polyacrylamide gels. SDS-PAGE analysis was performed according to the Laemmli method using a Bio-Rad gel apparatus.

Flow cytometry analysis for DNA fragmentation and DAPI staining. Cell counts were performed using a hemocytometer. Approximately 5x105/ml DU-145 cells were suspended in $100 \mu \mathrm{l}$ of PBS and supplemented with $200 \mu 199 \%$ ethanol while being gently vortexed. The cells were incubated at $4^{\circ} \mathrm{C}$ for at least $1 \mathrm{~h}$. After fixing, the cells were washed with PBS with $2 \%$ fetal bovine serum (FBS) and suspended in $250 \mu 11.12 \%$ sodium citrate buffer together with $12.5 \mu \mathrm{g}$ of RNase. Incubation was continued at $37^{\circ} \mathrm{C}$ for $30 \mathrm{~min}$. The cellular DNA was then stained by applying $250 \mu \mathrm{l}$ propidium iodide (PI) for $30 \mathrm{~min}$. Fluorescence emitted from the PI-DNA complex was analyzed at $488 \mathrm{~nm}$. The stained cells were analyzed by fluorescent activated cell sorting (FACS) on a FC 500 (Beckman Coulter) flow cytometer for relative DNA content based on red fluorescence. DU-145 cells were treated with TRAIL $(50 \mathrm{ng} / \mathrm{ml})$ in the presence or absence of tunicamycin $(2 \mu \mathrm{g} / \mathrm{ml})$. The cells were fixed with $4 \%$ paraformaldehyde on a glass slide for $30 \mathrm{~min}$ at room temperature. Cells were then washed with PBS, incubated with $300 \mathrm{nM}$ DAPI (MicroProbe, San Jose, CA, USA) for $10 \mathrm{~min}$, and examined by fluorescence microscopy. Apoptotic cells were identified by condensation and fragmentation of nuclei. DAPI staining experiments were performed in duplicate.

Transfection with small interfering RNA (siRNA), stable transfection and luciferase assay in DU-145 cells. DU-145 cells were plated in 6-well plates and allowed to adhere for $24 \mathrm{~h}$. On the day of tansfection, $10 \mu \mathrm{l}$ Lipofectamine 2000 (Invitrogen, Carlsbad, CA, USA) were added to $50 \mathrm{nmol} / 1 \mathrm{siRNA}$ in a final volume of $100 \mu \mathrm{l}$ OPTI-MEM medium. After $48 \mathrm{~h}$ of transfection, cells were treated with TRAIL for $2 \mathrm{~h}$. The DU-145 cells were stably transfected with the pcDNA 3.1-cIAP2 plasmid or control plasmid pcDNA 3.1 vector using Lipofectamine as instructed by the manufacturer (Invitrogen). After $48 \mathrm{~h}$ of incubation, transfected cells were selected in primary cell culture medium containing $700 \mu \mathrm{g} / \mathrm{ml} \mathrm{G} 418$ (Invitrogen). After 2 or 3 weeks, to rule out the possibility of clonal differences between the generated stable cell lines, the pooled DU-145/pcDNA 3.1 and DU-145/cIAP2 clones were tested for cIAP2 expression by immunoblotting before being used in the study. The luciferase cIAP2 and NF- $\kappa$ B plasmids were a gift from Dr T.H. Lee (Yeonsei University). Cells were seeded in 6-well plates at $2.5 \times 10^{5}$ cells/plate and grown for $24 \mathrm{~h}$ before transfection. Cells were co-transfected with $1 \mu \mathrm{g}$ of plasmid and $1 \mu \mathrm{g}$ of the pCMV galactosidase normalization plasmid by 4 -h incubation with Lipofectamine reagent (Invitrogen). Luciferase and galactosidase activities were determined according to the manufacturer's instructions (Promega, Madison, WI, USA).

Reverse transcription ( $R T)-P C R$ analysis. Total RNA was extracted from DU-145 cells using the TRIzol reagent (Invitrogen). A cDNA was synthesized from $2 \mu \mathrm{g}$ of total RNA using Moloney murine leukemia virus (MMLV) reverse transcriptase (Takara Co. Ltd., Japan). Human DR5 mRNA was amplified using the sense primer 5'-AAG ACC CTT GTG CTC GTT GT-3' and the antisense primer 5'-GAC ACA TTC GAT GTC ACT CCA-3'. The PCR cycling conditions (35 cycles) were chosen as follows: $30 \mathrm{sec}$ at $94^{\circ} \mathrm{C}, 45 \mathrm{sec}$ at $60^{\circ} \mathrm{C}, 30 \mathrm{sec}$ at $72^{\circ} \mathrm{C}$ for DR5 with a subsequent 5 -min extension at $72^{\circ} \mathrm{C}$. Reaction products were analyzed on $1.0 \%$ agarose gels and bands were visualized by ethidium bromide (EtBr).

Statistical analyses. The difference between the treated and control cells were analyzed by the Student's t-test, and a probability of $\mathrm{p}<0.05$ was considered significant.

\section{Results}

Tunicamycin sensitizes prostate cancer cells to TRAIL-induced apoptosis. To investigate the effect of tunicamycin on TRAILinduced cytotoxicity, DU-145 human prostatic adenocarcinoma cells were treated with TRAIL in the presence or absence of tunicamycin. DU- 145 cells were pre-treated with various concentrations of tunicamycin for $20 \mathrm{~h}$ and then exposed to TRAIL for $4 \mathrm{~h}$. Cells were moderately sensitive to either tunicamycin or TRAIL alone. However, pre-treatment with tunicamycin enhanced TRAIL-induced cytotoxicity (Fig. 1A). When apoptosis was examined by PI staining, we found that apoptosis was induced by $8.5 \%$ with tunicamycin, by $12.5 \%$ with TRAIL, and by $45 \%$ with the combination of both (Fig. 1B). Cells were then pre-treated with tunicamycin $(2 \mu \mathrm{g} / \mathrm{ml})$ for $20 \mathrm{~h}$, followed by 
$\mathbf{A}$

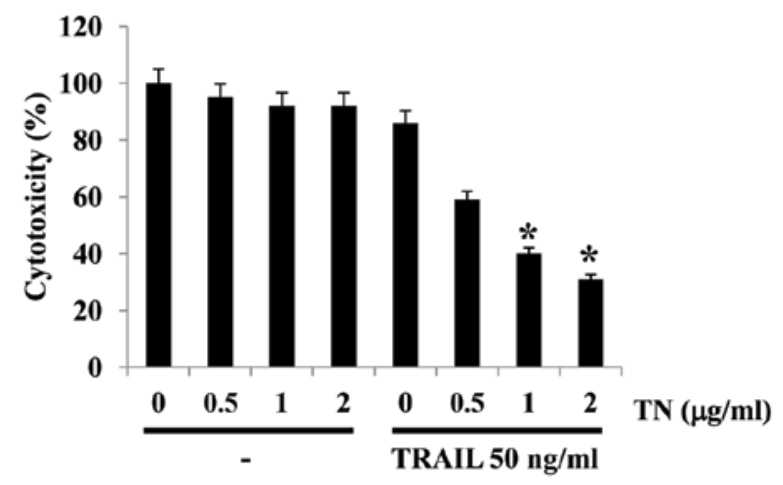

C

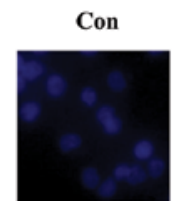

$2 \%$

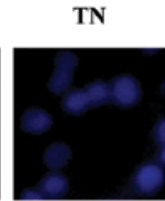

$7 \%$
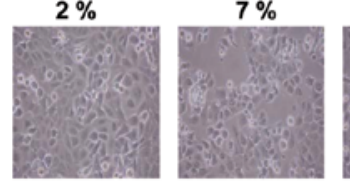

TRAIL

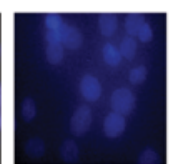

$10 \%$

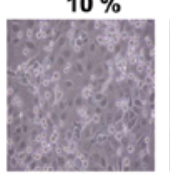

TN + TRAIL

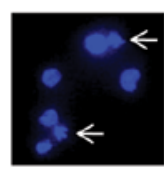

$50 \%$

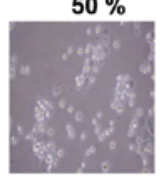

B

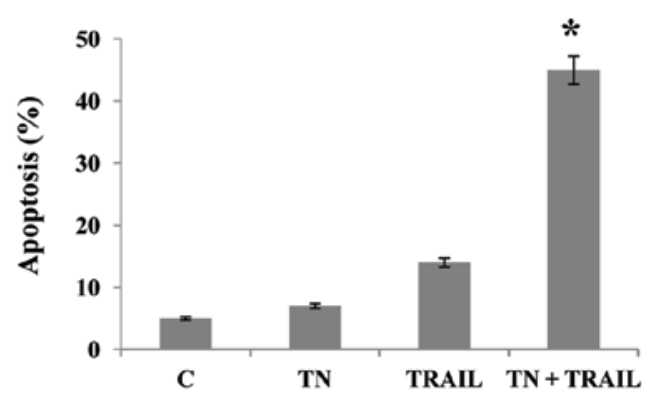

D

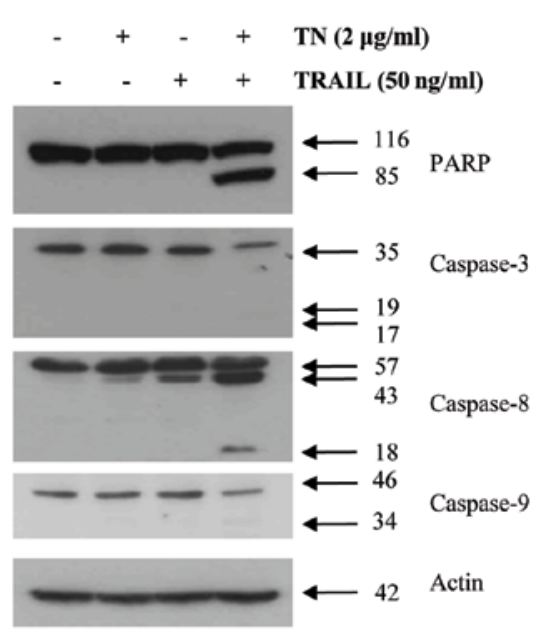

Figure 1. Tunicamycin enhances TRAIL-induced DU-145 cell death. (A) Cells were pre-treated with various concentrations of tunicamycin for $20 \mathrm{~h}$ before exposure to TRAIL $(50 \mathrm{ng} / \mathrm{ml})$ for $4 \mathrm{~h}$. Cell viability was then analyzed by trypan blue exclusion assay. Data represent the means \pm standard error of the mean (SEM) of 3 samples. " $\mathrm{p}<0.05$ compared to tunicamycin plus TRAIL-treated cells. (B) Cells were treated for $4 \mathrm{~h}$ with TRAIL (50 ng/ml) in the presence or absence of $2 \mu \mathrm{g} / \mathrm{ml}$ tunicamycin for $20 \mathrm{~h}$. After treatment, apoptosis was detected by FACS analysis. C, control, TN, tunicamycin, TN + TRAIL, TRAIL $50 \mathrm{ng} / \mathrm{ml}$ plus tunicamycin $2 \mu \mathrm{g} / \mathrm{ml}$. Data represent the means \pm SEM of 3 samples. ${ }^{*} \mathrm{p}<0.05$ compared to tunicamycin plus TRAIL-treated cells. (C) Cells were treated with $2 \mu \mathrm{g} / \mathrm{ml}$ tunicamycin for $20 \mathrm{~h}$ and were then treated with TRAIL $(50 \mathrm{ng} / \mathrm{ml})$ for $4 \mathrm{~h}$. Cell death was determined by DAPI staining. (D) Cells were pre-treated with tunicamycin for $20 \mathrm{~h}$ and then treated with TRAIL for $4 \mathrm{~h}$. Whole-cell extracts were prepared and analyzed by western blotting using antibodies against PARP, caspase-3, caspase-8 and caspase-9. Error bars represent SEM of 3 separate experiments.

exposure to TRAIL $(50 \mathrm{ng} / \mathrm{ml})$ for $4 \mathrm{~h}$. The results indicated that tunicamycin and TRAIL treatment alone induced $7 \%$ and $10 \%$ apoptosis, respectively. Combination treatment enhanced apoptosis by $50 \%$ (Fig. 1C). We then examined the effect of tunicamycin, TRAIL, and their combination on the activation of caspase-3, caspase- 8 , caspase- 9 and PARP cleavage. We found that although tunicamycin and TRAIL had little effect on the caspases and PARP, combination treatment was highly effective (Fig. 1D). Taken together, our results indicate that tunicamycin enhances TRAIL-induced apoptosis.

Tunicamycin induces the expression of TRAIL receptors, DR4 and DR5, in cancer cell lines. To determine how tunicamycin potentiates TRAIL-induced apoptosis, we investigated its effects on the TRAIL receptors, DR4 and DR5. DU-145 cells were treated with various concentrations of tunicamycin for $24 \mathrm{~h}$, and whole-cell extracts were prepared and examined for expression of DR4 and DR5 proteins. Tunicamycin induced the expression of DR4 and DR5 (Fig. 2A, left panel) in a dosedependent manner, with optimum induction occurring at around
1 to $2 \mu \mathrm{g} / \mathrm{ml}$. The time-dependence of DR induction was also examined. Tunicamycin induced the expression of DR4 and DR5 (Fig. 2A, right panel) in a time-dependent manner. To determine whether the induction of TRAIL receptors by tunicamycin occured at the transcriptional level, we examined mRNA for DR4 and DR5 expression after the cells were treated with various concentrations of tunicamycin for different time periods. A DR5 transcript was induced in a dose- and time-dependent manner by tunicamycin (Fig. 2B), suggesting that tunicamycin acts at the transcriptional level. We also investigated whether the upregulation of DR5 and DR4 by tunicamycin is specific to PC3 or whether it also occurs in other cell types. Prostate cancer cells (PC3 and LNCaP), colon cancer cells (HCT116 and HT29), cervical cancer cells (HeLa and Caski), breast cancer cells (MDA231), and lung cancer cells (A549 cells) were exposed to tunicamycin $(2 \mu \mathrm{g} / \mathrm{ml})$ for $24 \mathrm{~h}$ and then examined for DR5 and DR4 protein expression. Tunicamycin induced the expression of DR5 (Fig. 2C, top panel) in the LNCaP, HCT116, HeLa, Caski and MDA231 cells. Tunicamycin induced the expression of DR4 (Fig. 2C, middle panel) in the PC3 HCT116, 
A
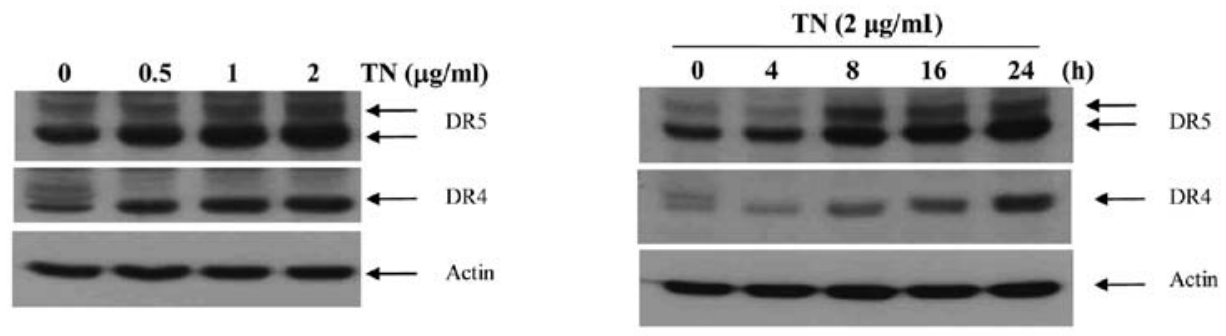

B
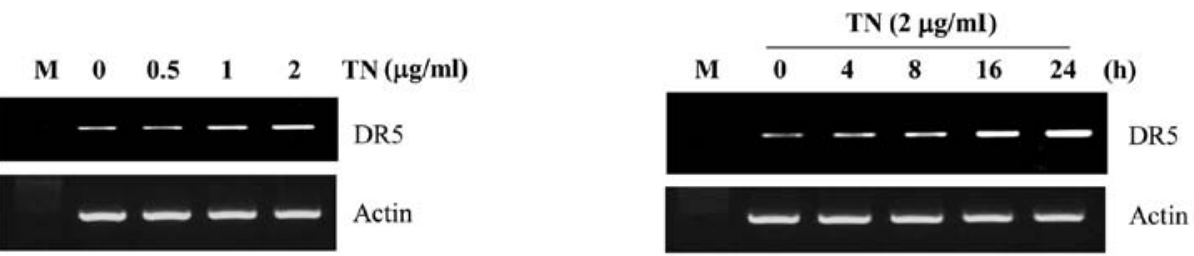

C

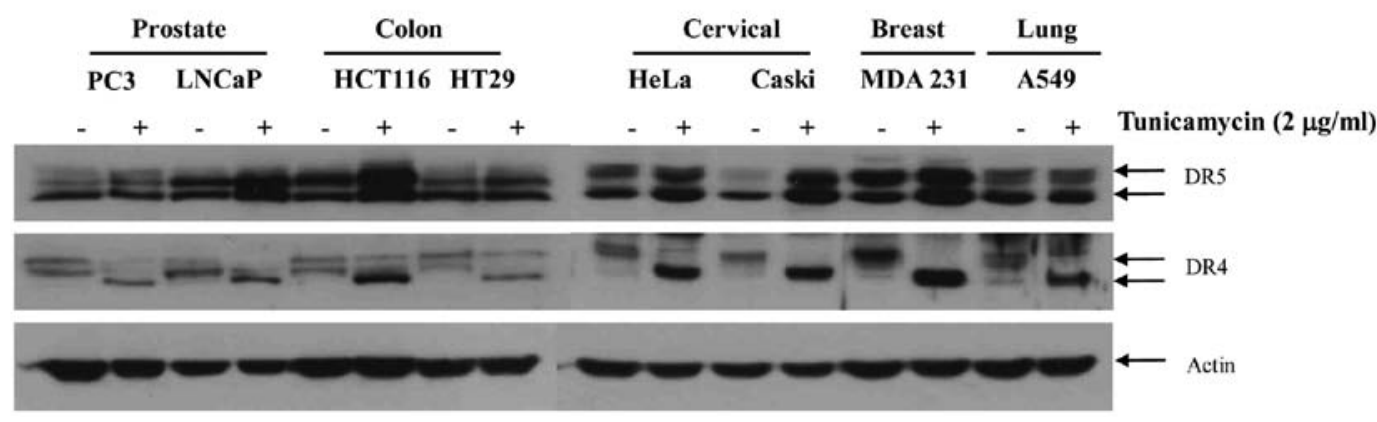

Figure 2. Tunicamycin-induced DR5 and DR4 expression. (A) DU-145 cells were treated with the indicated doses of tunicamycin at the indicated times. Whole cell extracts were prepared and analyzed for DR4 and DR5 expression by western blotting. (B) Tunicamycin-induced DR5 gene expression. DU-145 cells were treated with the indicated doses of tunicamycin at the indicated times, and total RNA was extracted and examined for expression of DR5 by RT-PCR. Actin was used as the internal control to show equal RNA loading. (C) Cells were treated with $2 \mu \mathrm{g} / \mathrm{ml}$ tunicamycin for $24 \mathrm{~h}$, and whole cell extracts were prepared and analyzed by western blotting. Equal amounts of protein $(20 \mu \mathrm{g})$ were separated by SDS-PAGE and immunoblotted. Equal protein loading was evaluated by actin. TN, tunicamycin.

HeLa, Caski, MDA231 and A549 cells. No significant induction of DR5 expression was noted in the PC3 and A549 cells. The induction of either DR4 or DR5 expression was minimal in PC3 prostate cancer and HT29 colon cancer cells after exposure to tunicamycin. These findings suggest that the upregulation of DR5 and DR4 by tunicamycin is not cell type-specific.

DR induction by tunicamycin is required for TRAIL-induced apoptosis. To determine the role of DR5 and DR4 in TRAILinduced apoptosis, we used siRNAs specific to DR5 and DR4 to downregulate their expression. The transfection of cells with siRNA for DR5 but not with the control siRNA reduced tunicamycin-induced DR5 expression (Fig. 3A). Similarly, the transfection of cells with siRNA for DR4 reduced the tunicamycin-induced DR4 expression (Fig. 3B). However, DR4 siRNA and DR5 siRNA had minimal effects on the tunicamycin-induced upregulation of DR4 and DR5. We then examined whether the suppression of DR5 and/or DR4 by siRNA can abrogate the sensitizing effects of tunicamycin on TRAIL-induced apoptosis using immunoblotting (Fig. 3C) and DAPI staining assays (Fig. 3D). The results revealed that the effect of tunicamycin on TRAIL-induced apoptosis was effectively abolished in cells transfected with both DR5 and DR4 siRNAs, whereas treatment with only DR4 siRNA or only DR5
siRNA had no effect. The silencing of both receptors abolished apoptosis to the same degree as the silencing of either DR4 or DR5, suggesting that both DR4 and DR5 are major players in TRAIL-induced apoptosis.

Tunicamycin downregulates the expression of cIAP2 but has no effect on XIAP, survivin and Bcl-2 family proteins. We then examined whether tunicamycin can affect the expression of any of the anti-apoptotic proteins. Cells were exposed to various concentrations of tunicamycin for $24 \mathrm{~h}$ and were then examined for the expression of $\mathrm{Bcl}-\mathrm{x}_{\mathrm{L}}$, Mcl-1, XIAP and survivin (Fig. 4A). Tunicamycin downregulated the transcript for cIAP2 in a dose- and time-dependent manner, suggesting that it acts at the transcriptional level (Fig. 4B). Tunicamycin may thus affect TRAIL-induced apoptosis not only through induction of DR4 and DR5 but also through the downregulation of cIAP2. We examined whether tunicamycin can affect cIAP2 promoter activity or related $\mathrm{NF}-\kappa \mathrm{B}$ promoter activity, as we expected that the cIAP2 promoter is regulated by the $\mathrm{NF}-\kappa \mathrm{B}$ transcription factor (data not shown).

Silencing of cIAP2 enhances TRAIL sensitization by tunicamycin which blocks cIAP2 expression. We investigated whether the downregulation of cIAP2 by tunicamycin is specific to 
$\mathbf{A}$

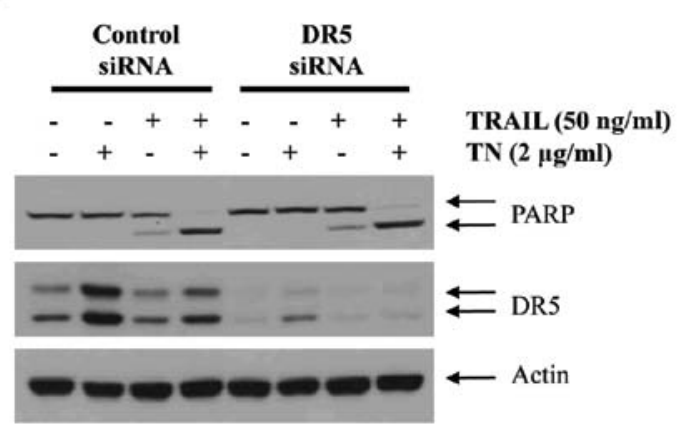

B

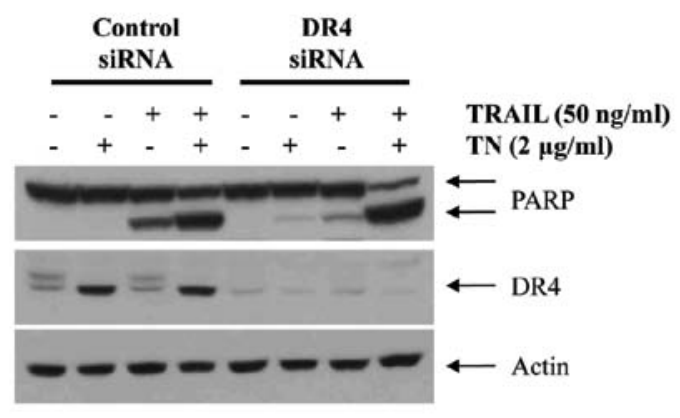

C

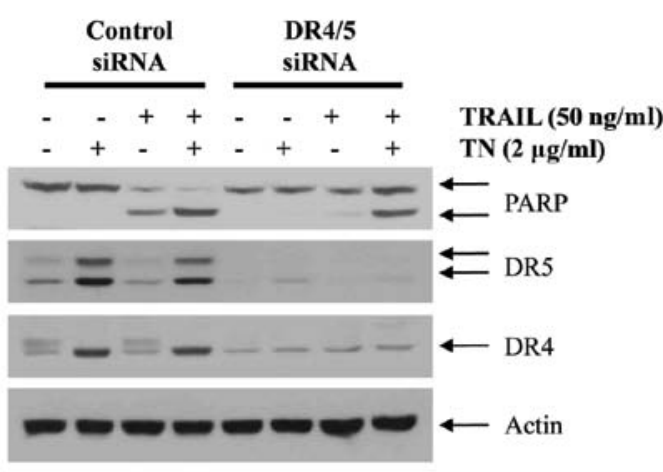

D

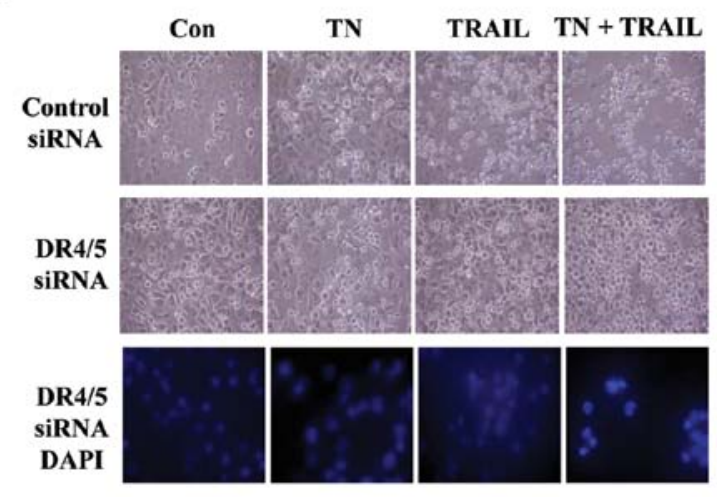

Figure 3. Effect of knockdown of death receptors (DRs) on tunicamycin-induced sensitization of TRAIL. DU-145 cells were transfected with (A) DR5 siRNA, (B) DR4 siRNA, and (C) combined DR4 and DR5 siRNA. After $48 \mathrm{~h}$, cells were pre-treated with tunicamycin for $20 \mathrm{~h}$ and then treated with TRAIL for $4 \mathrm{~h}$. Whole cell extracts were prepared and analyzed by western blotting using antibodies against PARP, DR4 and DR5. (D) Cells were treated with $2 \mu \mathrm{g} / \mathrm{ml}$ tunicamycin for $20 \mathrm{~h}$ and then treated with TRAIL $(50 \mathrm{ng} / \mathrm{ml}$ ) for $4 \mathrm{~h}$. Cell death was determined by DAPI staining. TN, tunicamycin.

DU-145 cells or whether it also occurs in other cell types (Fig. 5A). The induction of cIAP2 was minimal in HeLa cervical cancer and A549 lung cancer cells after exposure to tunicamycin. These findings suggest that the downregulation of cIAP2 by tunicamycin is not cell type-specific. We examined the functional significance of cIAP2 downregulation in the enhancement of TRAIL-induced apoptosis by tunicamycin using stable cell lines overexpressing cIAP2 (\#10,\#16) (Fig. 5B, top panel). The apoptotic morphology observed in the control cells treated with tunicamycin plus TRAIL was not observed in cIAP2 \#10 and cIAP2 \#16 cells (data not shown). Furthermore, we found that the increase in the sub-G1 cell population by tunicamycin plus TRAIL was effectively blocked in cIAP2-overexpressing cells (Fig. 5B, bottom panel). We then investigated whether the silencing of cIAP2 or the overexpression of cIAP2 can block TRAIL-induced cell death and inhibit TRAIL sensitization in prostate cancer cells. DU-145 cells were successfully transfected with control or specific siRNAs against cIAP2. After $48 \mathrm{~h}$, cells were exposed to TRAIL for $4 \mathrm{~h}$, harvested, and lysates subjected to western blotting. The expression of cIAP2 was shown to be reduced in cells treated with specific siRNA compared to control siRNA (Fig. 5C, bottom panel). The reduction in the expression of cIAP2 significantly enhanced TRAIL-induced cell death (Fig. 5C, top panel). These results indicate that apoptosis by tunicamycin plus TRAIL is associated with cIAP2 expression in DU-145 cells.

\section{Discussion}

In this study, we show that the antibiotic component, tunicamycin, can enhance the apoptotic effect of TRAIL against prostate cancer cells. The mechanism by which tunicamycin mediates its effects on TRAIL-induced apoptosis involve the induction of TRAIL receptors and the downregulation of cIAP2. We found that the induction of TRAIL receptors by tunicamycin was not cell type-specific but was observed in a wide variety of cell types, including colon, cervical and breast cancer cells (Fig. 2C).

The induction of TRAIL receptor expression by tunicamycin treatment resulted in the sensitization of DU-145 cells to TRAIL-induced apoptosis. Furthermore, caspase-3, -8 and -9 were activated only when tunicamycin and TRAIL were provided together (Fig. 1D), and the activation of these caspases was blocked in the presence of z-VAD, a pan caspase inhibitor (data not shown). Caspase-8 is known to act directly downstream of the TRAIL receptors and Bid is a known mediator connecting the DR pathway to the mitochondrial apoptotic pathway (22-24). Importantly, the downregulation of DR4 and DR5 expression using DR4 and DR5 siRNAs efficiently reduced the tunicamycin-dependent sensitization to TRAIL-induced apoptosis (Fig. 3). The upregulation of DR4 and DR 5 by tunicamycin thus sensitizes prostate cancer cells to TRAIL-induced apoptosis. Moreover, the combined treatment 
A

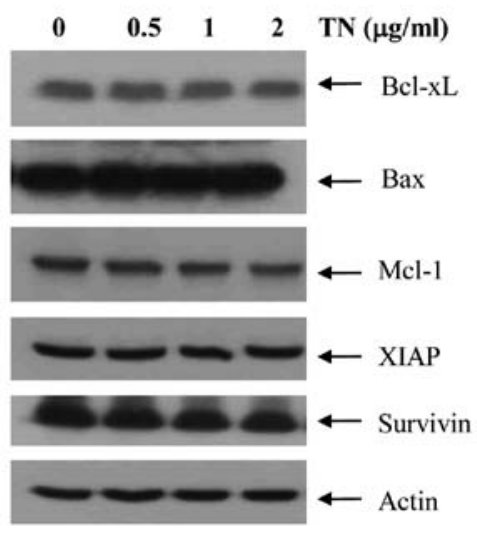

C
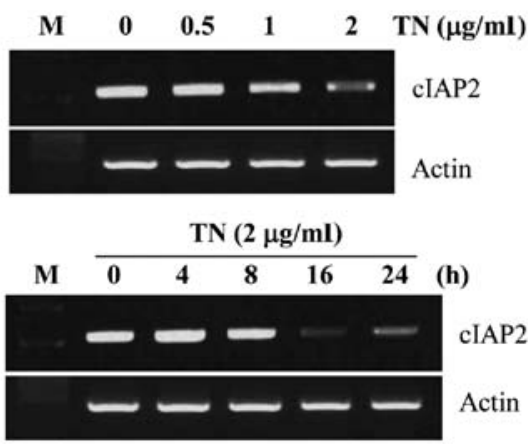

B

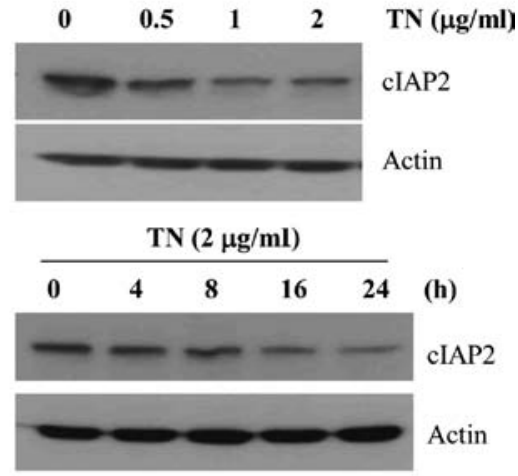

Figure 4. Effect of tunicamycin on anti-apoptotic protein and cIAP2 protein and mRNA expression in DU-145 cells. (A) DU-145 cells were treated with the indicated concentrations of tunicamycin. Whole cell extracts were prepared and analyzed by western blotting using relevant antibodies. (B) Tunicamycin decreased cIAP2 expression. DU-145 cells were treated with tunicamycin at various concentrations and for different times. Whole cell extracts were prepared and analyzed by western blotting using cIAP2 antibody. (C) Tunicamycin-induced cIAP2 gene expression. DU-145 cells were treated with the indicated doses of tunicamycin for the indicated times, total RNA was isolated and RT-PCR analysis was performed. A representative study is shown; 2 additional experiments yielded similar results. TN, tunicamycin.

A

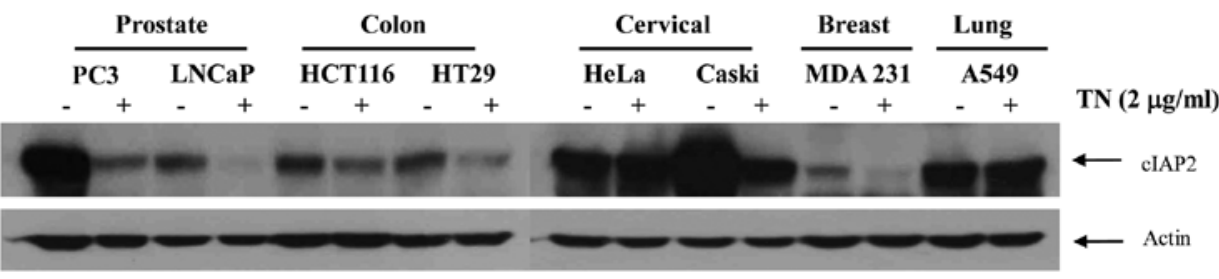

B

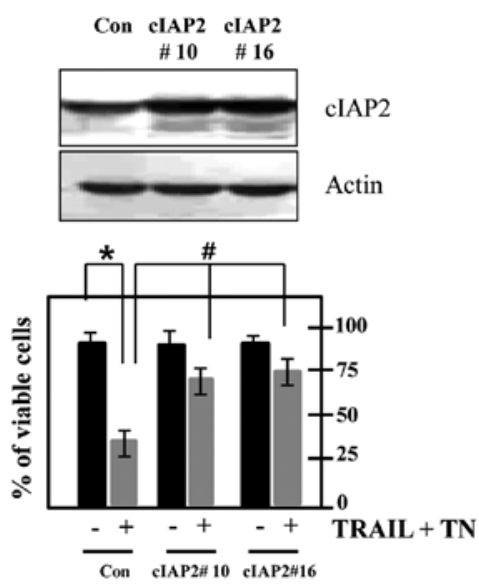

C
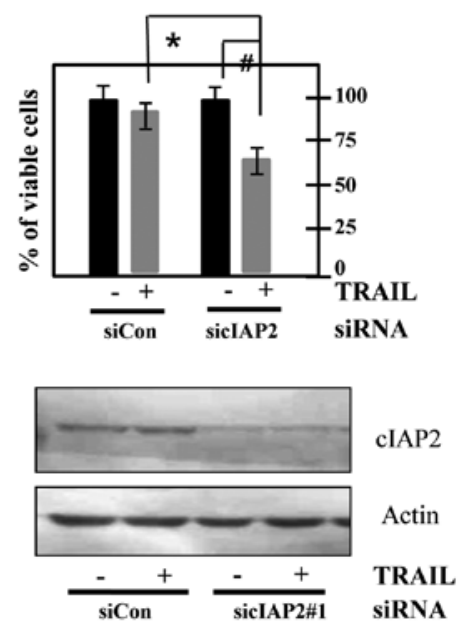

Figure 5. Tunicamycin-induced cIAP2 downregulation critically contributes to tunicamycin-stimulated TRAIL-induced apoptosis. (A) DU-145 cells were treated with tunicamycin for $24 \mathrm{~h}$ and western blotting of cIAP2 and actin was performed. (B) The protein levels of cIAP2 were examined by western blotting using anti-cIAP2 antibody in DU-145 cells stably transfected with control vector or plasmid cIAP2. Control cells (Con) and the cells stably overexpressing cIAP2 were treated with tunicamycin and TRAIL for $24 \mathrm{~h}$. Cell viability was assessed using a sub-G1 fraction by flow cytometry. Data represent the means \pm SEM of 3 samples; " $\mathrm{p}<0.05$ compared with untreated cells and ${ }^{*} \mathrm{p}<0.05$ compared with the control cells treated with tunicamycin plus TRAIL. (C) To examine the effect of cIAP2 downregulation on TRAL-induced apoptosis, DU-145 cells were transfected with the control siRNA or cIAP2 siRNA, incubated for $24 \mathrm{~h}$ and further treated with or without $50 \mathrm{ng} / \mathrm{ml}$ TRAIL for $4 \mathrm{~h}$. Cellular viability was determined using a sub-G1 fraction by flow cytometry. Data represent the means \pm SEM of 3 samples; ${ }^{p} \mathrm{p}<0.05$ compared with transfection with control siRNA or cIAP2 siRNA with TRAIL; ${ }^{*} \mathrm{p}<0.05$ compared with the cells transfected with cIAP2 siRNA but untreated with TRAIL. Western blotting of cIAP2 was done to confirm the downregulation of cIAP2 by siRNA transfection. Actin levels were assessed to show equal gel loading. TN, tunicamycin. 
with both DR4 and DR5 siRNAs blocked this sensitization (Fig. 3C); however, either DR4 or DR5 siRNA alone did not block the sensitizing effect of tunicamycin on TRAIL-induced apoptosis (Fig. 3A and B). Both TRAIL receptors therefore play a functional role. Our findings indicate that DR4 and DR5 upregulation accounts, at least in part, for the sensitizing effect of tunicamycin on TRAIL-induced apoptosis. Our findings are in agreement with those from other studies reporting that tunicamycin upregulates DR5 expression and sensitizes TRAIL-induced apoptosis in a p53-independent manner (25). Combined treatment with tunicamycin plus TRAIL may thus be useful for p53-deficient cancer cells. A number of studies have demonstrated that DR5 upregulation may be a promising strategy for sensitizing cancer cells to TRAIL-induced apoptosis $(26,27)$. Chen et al (28) reported tunicamycin-induced upregulation of CHOP. CHOP protein was first identified as a member of the CCAAT/enhancer binding proteins (C/EBPs) that dimerize with transcription factor C/EBP and LAP (29).

Besides the induction of TRAIL receptors, the downregulation of cIAP2 by tunicamycin may also lead to the enhancement of TRAIL-induced apoptosis. Tunicamycin was found to have little effect on other anti-apoptotic proteins, including Mcl-1 and survivin (Fig. 4A). Several apoptotic pathways are induced in prostate cancer cells by tunicamycin. We previously provided evidence that tunicamycin promotes the induction of the TRAIL receptor not only in melanoma but also in prostate cancer cells $(25,30)$. In this study, we show that the reduction of cIAP2 by tunicamycin in the prostate cancer cell line, DU-145, correlates with an increase in the number of apoptotic cells. In certain prostate cancer cells, tunicamycin induces the concomitant upregulation of TRAIL receptors and the activation of a gene program of apparent opposite function, characterized by the induction of the anti-apoptotic IAP family member, cIAP2, a $\mathrm{NF}-\kappa \mathrm{B}$ target gene. cIAP2 expression was significantly modulated at both the mRNA and protein levels by tunicamycin in a cell context-dependent manner (Fig. 5). In addition, cIAP2 protein levels can be regulated by alternative signaling pathways either in parallel with or in addition to NF- $\kappa \mathrm{B}$ signaling. cIAP2 and XIAP have been reported to be upregulated in a Ras-dependent manner through receptor tyrosine kinase activation (31), as well as through other signaling pathways including PI3K $(32,33)$, protein kinase C $\Delta(34)$ and cAMP (35). In DU-145 cells, tunicamycin induces the NF- $\mathrm{KB}$-mediated downregulation of cIAP2. This finding presents the possibility of being able to bypass $N F-\kappa B$ inhibition to induce sensitivity and eliminate the inherent difficulty in trying to inhibit NF- $\mathrm{BB}$.

In conclusion, in this study we investigated the molecular mechanisms by which tunicamycin enhances TRAIL-induced apoptosis in DU-145 cells. We found that tuicamycin effectively sensitizes DU-145 prostate cancer cells to TRAIL-induced apoptosis through the downregulation of cIAP2 and upregulation of DR5. Tunicamycin as a potential TRAIL sensitizer may enhance therapeutic outcome by either lowering TRAIL resistance or increasing the damage of cancer cells.

\section{Acknowledgements}

This study was supported by the Korea Research Foundation Grant funded by the Korean Government (KRF-2008331-C00255) and Basic Science Research Program through the National Research Foundation of Korea (NRF) funded by the Ministry of Education, Science and Technology (20100009064).

\section{References}

1. Ashkenazi A, Pai RC, Fong S, Leung S, Lawrence DA, Marsters SA, Blackie C, Chang L, McMurtrey AE, Hebert A, DeForge L, Koumenis IL, Lewis D, Harris L, Bussiere J, Koeppen H, Shahrokh Z and Schwall RH: Safety and antitumor activity of recombinant soluble Apo2 ligand. J Clin Invest 104: 155-162, 1999.

2. Keane MM, Ettenberg SA, Nau MM, Russell EK and Lipkowitz S: Chemotherapy augments TRAIL-induced apoptosis in breast cell lines. Cancer Res 59: 734-741, 1999.

3. Lawrence D, Shahrokh Z, Marsters S, Achilles K, Shih D, Mounho B, Hillan K, Totpal K, DeForge L, Schow P, Hooley J, Sherwood S, Pai R, Leung S, Khan L, Gliniak B, Bussiere J, Smith CA, Strom SS, Kelley S, Fox JA, Thomas D and Ashkenazi A: Differential hepatocyte toxicity of recombinant Apo2L/TRAIL versions. Nat Med 7: 383-385, 2001.

4. Pitti RM, Marsters SA, Ruppert S, Donahue CJ, Moore A and Ashkenazi A: Induction of apoptosis by Apo-2 ligand, a new member of the tumor necrosis factor cytokine family. J Biol Chem 271: 12687-12690, 1996.

5. Walczak H, Miller RE, Ariail K, Gliniak B, Griffith TS, Kubin M, Chin W, Jones J, Woodward A, Le T, Smith C, Smolak P, Goodwin RG, Rauch CT, Schuh JC and Lynch DH: Tumoricidal activity of tumor necrosis factor-related apoptosis-inducing ligand in vivo. Nat Med 5: 157-163, 1999.

6. Adams JM and Cory S: The Bcl-2 apoptotic switch in cancer development and therapy. Oncogene 26: 1324-1337, 2007.

7. Nachmias B, Ashhab $Y$ and Ben-Yehuda D: The inhibitor of apoptosis protein family (IAPs): an emerging therapeutic target in cancer. Semin Cancer Biol 14: 231-243, 2004.

8. Liu Z, Sun C, Olejniczak ET, Meadows RP, Betz SF, Oost T, Herrmann J, Wu JC and Fesik SW: Structural basis for binding of Smac/DIABLO to the XIAP BIR3 domain. Nature 408: 1004-1008, 2000.

9. Srinivasula SM, Hegde R, Saleh A, Datta P, Shiozaki E, Chai J, Lee RA, Robbins PD, Fernandes-Alnemri T, Shi Y and Alnemri ES: A conserved XIAP-interaction motif in caspase-9 and Smac/DIABLO regulates caspase activity and apoptosis. Nature 410: 112-116, 2001.

10. Wu G, Chai J, Suber TL, Wu JW, Du C, Wang X and Shi Y: Structural basis of IAP recognition by Smac/DIABLO. Nature 408: 1008-1012, 2000

11. Morizane Y,Honda R, Fukami K and Yasuda H: X-linked inhibitor of apoptosis functions as ubiquitin ligase toward mature caspase-9 and cytosolic Smac/DIABLO. J Biochem 137: 125-132, 2005.

12. Suzuki Y, Nakabayashi Y and Takahashi R: Ubiquitin-protein ligase activity of $\mathrm{X}$-linked inhibitor of apoptosis protein promotes proteasomal degradation of caspase-3 and enhances its antiapoptotic effect in Fas-induced cell death. Proc Natl Acad Sci USA 98: 8662-8667, 2001.

13. Zhang M, Latham DE, Delaney MA and Chakravarti A: Survivin mediates resistance to antiandrogen therapy in prostate cancer. Oncogene 24: 2474-2482, 2005.

14. Zhang M, Mukherjee N, Bermudez RS, Latham DE, Delaney MA, Zietman AL, Shipley WU and Chakravarti A: Adenovirusmediated inhibition of survivin expression sensitizes human prostate cancer cells to paclitaxel in vitro and in vivo. Prostate 64: 293-302, 2005

15. Amantana A, London CA, Iversen PL and Devi GR: X-linked inhibitor of apoptosis protein inhibition induces apoptosis and enhances chemotherapy sensitivity in human prostate cancer cells. Mol Cancer Ther 3: 699-707, 2004.

16. LaCasse EC, Cherton-Horvat GG, Hewitt KE, Jerome LJ, Morris SJ, Kandimalla ER, Yu D, Wang H, Wang W, Zhang R, Agrawal S, Gillard JW and Durkin JP: Preclinical characterization of AEG35156/GEM 640, a second-generation antisense oligonucleotide targeting X-linked inhibitor of apoptosis. Clin Cancer Res 12: 5231-5241, 2006.

17. McEleny $\mathrm{K}$, Coffey R, Morrissey C, Williamson K, Zangemeister-Wittke U, Fitzpatrick JM and Watson RW: An antisense oligonucleotide to cIAP-1 sensitizes prostate cancer cells to fas and TNFalpha mediated apoptosis. Prostate 59: 419-425, 2004 
18. Chawla-Sarkar M, Bae SI, Reu FJ, Jacobs BS, Lindner DJ and Borden EC: Downregulation of Bcl-2, FLIP or IAPs (XIAP and survivin) by siRNAs sensitizes resistant melanoma cells to Apo2L/TRAIL-induced apoptosis. Cell Death Differ 11: 915-923, 2004.

19. Yamaguchi Y, Shiraki K, Fuke H, Inoue T, Miyashita K, Yamanaka Y, Saitou Y, Sugimoto K and Nakano T: Targeting of X-linked inhibitor of apoptosis protein or survivin by short interfering RNAs sensitize hepatoma cells to TNF-related apoptosis-inducing ligand- and chemotherapeutic agent-induced cell death. Oncol Rep 14: 1311-1316, 2005.

20. Zhang S, Ding F, Luo A, Chen A, Yu Z, Ren S, Liu Z and Zhang L: $\mathrm{XIAP}$ is highly expressed in esophageal cancer and its downregulation by RNAi sensitizes esophageal carcinoma cell lines to chemotherapeutics. Cancer Biol Ther 6: 973-980, 2007.

21. Naumann U, Bähr O, Wolburg H, Altenberend S, Wick W, Liston P, Ashkenazi A and Weller M: Adenoviral expression of XIAP antisense RNA induces apoptosis in glioma cells and suppresses the growth of xenografts in nude mice. Gene Ther 14: $147-161,2007$.

22. Li H, Zhu H, Xu CJ and Yuan J: Cleavage of BID by caspase 8 mediates the mitochondrial damage in the Fas pathway of apoptosis. Cell 94: 491-501, 1998

23. Luo X, Budihardjo, Zou H, Slaughter C and Wang X: Bid, a Bcl2 interacting protein, mediates cytochrome $\mathrm{c}$ release from mitochondria in response to activation of cell surface death receptors. Cell 94: 481-490, 1998.

24. Yamada H, Tada-Oikawa S, Uchida A and Kawanishi S: TRAIL causes cleavage of bid by caspase- 8 and loss of mitochondrial membrane potential resulting in apoptosis in BJAB cells. Biochem Biophys Res Commun 265: 130-133, 1999.

25. Shiraishi T, Yoshida T, Nakata S, Horinaka M, Wakada M, Mizutani Y, Miki T and Sakai T: Tunicamycin enhances tumor necrosis factor-related apoptosis-inducing ligand-induced apoptosis in human prostate cancer cells. Cancer Res 65: 6364$6370,2005$.

26. Ravi R, Bedi GC, Engstrom LW, Zeng Q, Mookerjee B, Gélinas C, Fuchs EJ and Bedi A: Regulation of death receptor expression and TRAIL/Apo2L-induced apoptosis by NF-kappaB. Nat Cell Biol 3: 409-416, 2001.
27. Kelley RF, Totpal K, Lindstrom SH, Mathieu M, Billeci K, Deforge L, Pai R, Hymowitz SG and Ashkenazi A: Receptorselective mutants of apoptosis-inducing ligand $2 /$ tumor necrosis factor-related apoptosis-inducing ligand reveal a greater contribution of death receptor (DR) 5 than DR4 to apoptosis signaling. J Biol Chem 280: 2205-2212, 2005.

28. Chen G, Fan Z, Wang X, Ma C, Bower KA, Shi X, Ke ZJ and Luo J: Brain-derived neurotrophic factor suppresses tunicamycininduced upregulation of CHOP in neurons. J Neurosci Res 85: 1674-1684, 2007.

29. Oyadomari S and Mori M: Roles of CHOP/GADD153 in endoplasmic reticulum stress. Cell Death Differ 11: 381-389, 2004.

30. Jiang CC, Chen LH, Gillespie S, Kiejda KA, Mhaidat N, Wang YF, Thorne R, Zhang XD and Hersey P: Tunicamycin sensitizes human melanoma cells to tumor necrosis factor-related apoptosisinducing ligand-induced apoptosis by up-regulation of TRAIL-R2 via the unfolded protein response. Cancer Res 67: 5880-5888, 2007.

31. Liu Z, Li H, Derouet M, Filmus J, LaCasse EC, Korneluk RG, Kerbel RS and Rosen KV: ras Oncogene triggers up-regulation of cIAP2 and XIAP in intestinal epithelial cells: epidermal growth factor receptor-dependent and -independent mechanisms of rasinduced transformation. J Biol Chem 280: 37383-37392, 2005.

32. Seol DW: Up-regulation of IAPs by PI-3K: a cell survival signalmediated antiapoptotic mechanism. Biochem Biophys Res Commun 377: 508-511, 2008.

33. Terragni J, Graham JR, Adams KW, Schaffer ME, Tullai JW and Cooper GM: Phosphatidylinositol 3-kinase signaling in proliferating cells maintains an anti-apoptotic transcriptional program mediated by inhibition of FOXO and non-canonical activation of NFkappaB transcription factors. BMC Cell Biol 9: 6, 2008.

34. Wang Q, Wang X and Evers BM: Induction of cIAP-2 in human colon cancer cells through PKC delta/NF-kappa B. J Biol Chem 278: 51091-51099, 2003.

35. Nishihara H, Kizaka-Kondoh S, Insel PA and Eckmann L: Inhibition of apoptosis in normal and transformed intestinal epithelial cells by cAMP through induction of inhibitor of apoptosis protein (IAP)-2. Proc Natl Acad Sci USA 100: 89218926, 2003. 